\title{
Impact of Pineapple Cultivation on the Increased Income of Pineapple Growers
}

\author{
S. S. Hasan*, M. A. Ali and M. I. Khalil \\ Department of Agricultural Extension \& Rural Development, Bangabandhu Sheikh Mujibur Rahman \\ Agricultural University, Gazipur-1706, Bangladesh \\ *Corresponding author and Email: shinuextn120@yahoo.com
}

Received: 31 October 2010

Accepted: 17 March 2011

\begin{abstract}
A study was conducted to determine the impact of pineapple cultivation on the income of pineapple growers of Madhupur upazila under Tangail District. The study also aimed at exploring the relationship between the selected characteristics of the respondents and their increased income from unit area. The study was conducted during the month of March and April, 2007. Seventy five respondents were selected as the sample for the study by using simple random sampling technique. Most of the respondents were middle aged (49.3\%), had primary level of education (56\%), possessed medium farm $(57.3 \%)$ and small family size $(85.3 \%)$. The respondents had medium organizational participation $(65.3 \%)$ and medium extension contact $(83.1 \%)$. It was found that most of the respondents had sufficient knowledge on pineapple cultivation along with favorable attitude towards pineapple cultivation. Kachu (Colocasia esculenta), turmeric (Curcuma longa), ginger (Zingiber officinale), jackfruit (Artocarpus heterophyllus) etc were the major crops used as intercrops with pineapple for proper utilization of land and higher economic return. It was also found from the study that most of the respondents belonged to the higher $(54.7 \%)$ income category as their average increased income was 146.72 thousand taka per annum.
\end{abstract}

Keywords: Pineapple cultivation, impact, increased income.

\section{Introduction}

Fruits play a vital role in the overall economic performance of Bangladesh. The production of fruits including pineapple is increasing day by day in Bangladesh. Among all the fruits produced in the country, pineapple ranks $4^{\text {th }}$ in terms of total cropping area and production. During 2002-03, total production of pineapple in the country was 154 thousand metric tons which was increased to 210 thousands metric tons during 2007-08 (Anonymous, 2009).

Generally, the ripen pineapple is consumed by the people of Bangladesh. Green pineapple is also used for making pickles. After extraction of its juice, the left over is used as livestock feed and also the tender leaves are used for the same purpose. Various food items like squash, syrup, jelly, etc. are produced from pineapple. Vinegar, alcohol, citric acid, calcium citrate etc are also produced from it. Pineapple is also recommended as medical diet for certain diseased persons (Moniruzzaman, 1988).

The tropical climate is better for pineapple cultivation. Generally, it is grown almost all over Bangladesh especially in hilly and high land where there is no water stagnation. Long time drought is harmful for the production of pineapple. Drought affects its quality, quantity and size. Although Bangladesh is not a tropical country, the climate and the soils of many parts of Bangladesh are much more suitable for pineapple production. It is widely cultivated in 
the districts of Sylhet, Moulvibazar, Chittagong, Bnandarban, Dhaka and Tangail. In 1999-2000, Bangladesh produced 148350 metric tons of pineapple from 14101 hectares. But the area under production and total production are increasing day by day. During 2006-07 the total area under pineapple production in Bangladesh was 16978 hectares and the production was 238360 metric tons (Anonymous, 2008).

At least ninety varieties of pineapple are cultivated in the world. In Bangladesh, however, three varieties of pineapple are mostly grown. The three varieties are: Giant Kew, Honey Queen and Ghorasal. In the study area, mainly Giant Kew variety of pineapple has intensively been cultivated by the farmers for the last few years (Mondal and Mrittunjoy, 1988). Apart from this variety, one local variety named "Asshina" is grown by a few farmers of the study area.

So, pineapple cultivation plays a vital role for socio-economic development of the pineapple growers of Tangail district (the study area) where once upon a time the hilly lands were mostly barren. The life style of the people of that area was under developed earlier. But after practicing pineapple cultivation following some improved techniques, the people of the study area uplifted their condition socio-economically. Researches especially regarding the impact of pineapple cultivation on the socio-economic status of the farmers are dearth. Providing pertinent information through research is a crucial need which might help in appropriate production policies of pineapple. The present study was undertaken:

1. To determine some socioeconomic characteristics of the pineapple growers of the concerned area.

2. To describe the impact of pineapple cultivation on the increased income of the pineapple growers.

3. To explore the relationships between each of the selected characteristics of the pineapple growers and their increased income from unit area.

\section{Methodology}

Pineapple is extensively cultivated in all over Madhupur Upazila in Tangail District. So Madhupur Upazila of Tangail District was purposively selected as the study area. Two villages ie., North Laufulia and South Laufulia of Alokdia Union and another two villages ie., Jalchatra and Moterbazar of Ausnara union under Modhupur Upazila were selected as the study area. Total number of farm families of the four villages were 375 . Out of these population, 75 respondents were selected as sample following simple random sampling technique as per the following formula given by Kothari (2004).

$$
\mathrm{n}=\frac{\mathrm{Z}^{2} \times \sigma^{2} \times \mathrm{N}}{(\mathrm{N}-1) \mathrm{e}^{2}+\mathrm{Z}^{2} \cdot \sigma^{2}}
$$

Where,

$$
\begin{aligned}
& \mathrm{n}=\text { Size of the sample } \\
& \mathrm{N}=\text { Size of the population } \\
& \mathrm{e}=\text { Acceptable error } \\
& \sigma=\text { Population standard deviation } \\
& \mathrm{Z}=\text { Standard normal variate at a given }
\end{aligned}
$$

confidence level

After calculation, $\mathrm{n}=75$

The data were collected from the selected respondents through personal interview using a pre-designed and pre-tested interview schedule.

\subsection{Measurement of the independent variables}

The independent variables of the study was age, education, family size, farm size, organizational participation, extension contact, knowledge about pine apple cultivation and attitude towards pineapple cultivation. Age of the respondents was measured in terms of years on the basis of her response. A score of one was assigned for each year of her age. Similarly 1 for each number of child. A score of one (1) was given to a respondent who has completed one year of schooling. A score of zero (0) was assigned to an illiterate respondent who cannot read and write at all. A respondent who could sign his/ her name 
only, his/her educational qualification was considered equal to one year of schooling and was given a score of one. Family size included all members of a household like husband, wife, children and other members who are living together in a family. Family size of a respondent could be measured by assigning a score of one (1) for each member of the family. Family farm size was estimated on the basis of the cultivated area either owned by a farmer or cultivated on share cropping, the area being estimated in terms of full benefit to the respondents. The total area of land thus obtained was considered as the farm size score of the respondent. Organizational participation was measured by the membership in different organizations and weights assigned as 0 for no participation, 1 for ordinary member, 2 for executive member and 3 for officer like president or secretary. Extension contact scores of the respondents were computed on the basis of their extension contact with different sources of information. Respondents were asked whether they contacted with those extension activities never, rarely, occasionally and frequently. Weights were assigned as 0 for never, 1 for rarely, 2 for occasionally and 3 for frequently. Thus a respondent's extension contact was obtained by adding the weights for his responses to all the sources of information. To measure the knowledge on pineapple cultivation, each respondent was asked to answer some related questions regarding pineapple cultivation. Score 2 was given for each correct answer, 1 was given for each partially correct answer and 0 was given for each incorrect answer. The summation of obtained scores against all those questions represented the knowledge score of any respondent. The attitude of the respondents towards pineapple cultivation was measured by asking his opinion upon some attitudinal statements. Score 5 was assigned to strongly agree statements, while scores 4, 3, 2 and 1 was assigned for agree, undecided, disagree and strongly disagree statements respectively. In case of negative attitudinal statement reverse score was assigned to each response. The summation of the obtained scores against those statements represented the attitude score of any respondent.

\subsection{Measurement of the dependent variable}

The dependent variable of the study was increased income from pineapple cultivation from a unit area. Pineapple cultivators of the study area earned some additional income other than their main source of pineapple cultivation. Increase income from various sources was calculated here. Respondent's income from different sources were listed in the interview schedule like increased return from lands, income due to intercropping, income from additional fruits other than pineapple, and income from timber trees. As for example many jackfruit trees are found in the study area and farmers earned healthy return both from jackfruit as well timber. Increased income from pineapple cultivation was calculated by asking the respondents about their income in thousand taka from the above mentioned additional sources other than pineapple. The summation of all the sources in thousand taka represents the increased income from pineapple cultivation of the respondents.

\section{Results and Discussion}

\subsection{Characteristics profile of the respondents}

Characteristics profile of the farmers were determined and presented in Table 1. It is revealed that most (about $80 \%$ ) of the respondents were young to middle aged having varying level of education with no illiteracy. Majority $(85 \%)$ of the farmers had small family and the mean (4.79) value was smaller in comparison with national average of Bangladesh which was 4.9 (Anonymous, 2009). Table 1 reveals that majority (about 93\%) of the farmers had small to medium farm size and about $81 \%$ of the farmers had medium extension contact. As regards to organizational participation, about 93\% had low to medium organizational participation. All most all (about 90\%) the respondents had $61-80 \%$ knowledge regarding modern techniques of pineapple cultivation and they also maintained a favorable $(84 \%)$ attitude towards pineapple cultivation. 
Table 1. Socio demographic characteristics profile

\begin{tabular}{|c|c|c|c|c|c|c|}
\hline Variables & Measurement & Categories & $\begin{array}{c}\text { Respondents } \\
\text { Number }\end{array}$ & $\begin{array}{c}\text { Respondents } \\
\%\end{array}$ & Mean & $\begin{array}{l}\text { Standard } \\
\text { Deviation }\end{array}$ \\
\hline \multirow{3}{*}{ Age } & \multirow{3}{*}{ Years } & Young $(<35)$ & 22 & 29.30 & \multirow{3}{*}{41.77} & \multirow{3}{*}{9.42} \\
\hline & & Middle (36-50) & 37 & 49.30 & & \\
\hline & & Old $(>50)$ & 16 & 21.31 & & \\
\hline \multirow{4}{*}{ Education } & \multirow{4}{*}{ Rated score } & Illiterate & 0 & 0 & \multirow{4}{*}{7.36} & \multirow{4}{*}{4.58} \\
\hline & & Primary & 41 & 54.7 & & \\
\hline & & Secondary & 21 & 28.0 & & \\
\hline & & $\begin{array}{l}\text { Above } \\
\text { secondary }\end{array}$ & 13 & 17.3 & & \\
\hline \multirow{3}{*}{ Family Size } & \multirow{3}{*}{ Rated score } & Small $(<5)$ & 64 & 85.30 & \multirow{3}{*}{4.79} & \multirow{3}{*}{1.75} \\
\hline & & Medium (5-6) & 9 & 12.00 & & \\
\hline & & Large $(>6)$ & 2 & 2.70 & & \\
\hline \multirow{4}{*}{ Farm Size } & \multirow{4}{*}{ Hectare } & Marginal $(>0.5)$ & 2 & 2.70 & \multirow{4}{*}{1.39} & \multirow{4}{*}{0.76} \\
\hline & & Small (0.51-1.0) & 27 & 36.00 & & \\
\hline & & Medium (1.01- & 43 & $\begin{array}{l}50.00 \\
57.30\end{array}$ & & \\
\hline & & Large $(>3.0)$ & 3 & 4.00 & & \\
\hline \multirow{3}{*}{$\begin{array}{l}\text { Organizational } \\
\text { participation }\end{array}$} & \multirow{3}{*}{ Rated score } & Low $(<2)$ & 21 & 28.00 & \multirow{3}{*}{2.96} & \multirow{3}{*}{0.85} \\
\hline & & Medium (2-4) & 49 & 65.30 & & \\
\hline & & High $(>4)$ & 5 & 6.70 & & \\
\hline \multirow{3}{*}{$\begin{array}{l}\text { Extension } \\
\text { contact }\end{array}$} & \multirow{3}{*}{ Rated score } & Low $(<4)$ & 1 & 1.30 & \multirow{3}{*}{6.97} & \multirow{3}{*}{1.59} \\
\hline & & Medium (4-8) & 61 & 81.30 & & \\
\hline & & High $(>8)$ & 13 & 17.40 & & \\
\hline \multirow{4}{*}{ Knowledge } & \multirow{4}{*}{$\begin{array}{l}\text { Selected } \\
\text { scale }\end{array}$} & $\begin{array}{l}\text { Up to } 60 \% \\
(<23)\end{array}$ & 2 & 2.70 & \multirow{4}{*}{27.79} & \multirow{4}{*}{2.25} \\
\hline & & $61-70 \%(23-27)$ & 28 & 37.30 & & \\
\hline & & $71-80 \%(28-31)$ & 40 & 53.30 & & \\
\hline & & $>80 \%(>31)$ & 5 & 6.70 & & \\
\hline \multirow{4}{*}{ Attitude } & \multirow{4}{*}{$\begin{array}{l}\text { Selected } \\
\text { scale }\end{array}$} & Highly & & & \multirow{4}{*}{54.88} & \\
\hline & & favorable $(>60)$ & 7 & 9.30 & & \\
\hline & & $\begin{array}{l}\text { Favorable (50- } \\
60)\end{array}$ & 63 & 84.00 & & 3.56 \\
\hline & & $\begin{array}{l}\text { Unfavorable } \\
(<60)\end{array}$ & 5 & 6.70 & & \\
\hline
\end{tabular}




\subsection{Increased income from pineapple cultivation from unit area}

The increased income of the respondents from pineapple cultivation from unit area ranged from 43 to 200 thousand taka with an average being 146.72 thousand taka. The respondents were classified into three categories according to increased income i. e., low, medium and high increased income from pineapple cultivation (Table 2).

It is indicated from Table 2 that most of the respondents of the study area belonged to high $(54.7 \%)$ increased income category followed by medium $(36 \%)$ and low $(9.3 \%)$ increased income category, respectively.

Pineapple growers of the study area earned a lot of money by some additional fruits like jackfruit (both fruits and timber were used). Intercropping with pineapple is a common practice in Bangladesh. Intercropping is the practice of growing of two or more crops in the same pineapple field at or about the same time. The main purpose of intercropping is that the failure of one component of intercropping will not affect the performance of the crop components, and yield advantage with economic benefit. In most of the cases, aroids or kachu (Colocasia esculenta) which was cultivated by cent percent respondents, turmeric (Curcuma longa), ginger (Zingiber officinale), jackfruit (Artocarpus heterophyllus) etc are extensively cultivated as intercrop with pineapple which is also a common practice in the study area. Farmers earned a great economic profit by intercropping of these crops with pineapple. Current market price of various items like fruits (Jackfruit), timber from mainly jackfruit, aroids, zinger and turmeric etc are very high valued. So the respondents in most of the cases earned a lot of additional income from these items besides pineapple.

\subsection{Relationship between selected characteristics of the respondents and their increased income from pineapple cultivation}

To ascertain the relationship of respondents' characteristics with increased income from pineapple cultivation, correlation analysis was used. Various relationships regarding the above aspects were depicted in Table 3 .

Table 2. Distribution of the respondents according to their increased income from pineapple cultivation

\begin{tabular}{l|l|l|l|l}
\hline Category $(000 '$ taka) & No. & Percentage & Mean & SD \\
\hline Low $(<75)$ & 7 & 9.3 & & \\
Medium $(75-150)$ & 27 & 36 & 146.72 & 45.04 \\
High $(<150)$ & 41 & 54.7 & & \\
\hline
\end{tabular}

Table 3. Relationship between selected characteristics and increased income from pineapple cultivation of the respondents

\begin{tabular}{lc}
\hline Independent Variable & Coefficient correlation value of ' $r$ ' \\
\hline Age & 0.034 \\
Education & $0.306^{* *}$ \\
Family size & -0.055 \\
Farm size & $0.352^{* *}$ \\
Organizational participation & 0.153 \\
Extension contact & 0.114 \\
Knowledge & $0.233^{*}$ \\
Attitude & $0.199^{*}$
\end{tabular}

** Correlation is significant at $1 \%$ level

* Correlation is significant at $5 \%$ level 
Table 3 shows that education of the respondents had positive and significant relationship with their increased income from pineapple cultivation. So it can be said that increased income from pineapple cultivation of the respondents depends on their education. Education broadens one's outlook on life and helps to understand the social, political, economic and cultural issues in the society. The higher the educational attainment of an individual, higher was his/her level of understanding of any phenomenon. It is very important to note that $100 \%$ respondents of the study area were educated, considerable proportion $45 \%$ had secondary to higher secondary level of education. This literacy of the respondents allowed them to have access to the print media which helped them to cultivate the high valued crops like pineapple. Haque et.al., (2004) and Alam (1998) also found similar result.

The relationship between farm size and increased income from pineapple cultivation was found to be positive and significant $r=0.352^{* *}$. It means that higher the farm size, the higher the income from pineapple cultivation. Mondol et.al., (2005) also found similar result. The knowledge of the respondents on pineapple cultivation was found to have significant relationship $\left(r=0.233^{*}\right)$ with the increased income. This means that knowledge on pineapple cultivation has a great influence on increased income from pineapple cultivation. The findings also indicated that the higher the knowledge of the respondents on pineapple cultivation the higher is the increased income. Rahman (1995) also found similar result. According to Table 3, the attitude of the respondents showed a positive and significant relationship with their increased income $(r=$ $0.199 *$ ) from pineapple cultivation. This means that attitude of the respondents towards pineapple cultivation has a great influence on their increased income.
Pineapple is mainly a crop of hilly areas in Bangladesh. The concerned study area was also a hilly area, where no other crops are extensively and commercially grown. So, the respondents cultivated mainly pineapple and developed their positive knowledge and attitude towards pineapple cultivation, which has a great impact on their increased income. The findings also confirmed that the more positive and favorable is the knowledge and attitude the higher is the increased income of the respondents.

\section{Conclusions}

Based on the above findings, it may be concluded that intercropping of other crops with pineapple plays a vital role for increasing income of the respondents. Aroids, ginger, turmeric, jackfruits etc are the widely used intercrops of that area. For getting a healthy economic return farmers should pay due attention for growing these crops considering all recommended practices.

Education, farm size, annual income, knowledge and attitude towards pineapple cultivation were positively correlated with the increased income form unit area of pineapple cultivation of the respondents of the study area. The change agents should pay more attention to address these issues properly for making the livelihood of pineapple growers sustainable.

\section{References}

Alam, M. M. 1998. Farm level status of HYV Rice in a selected union of Gazipur District. M. Sc thesis, Department of Agricultural Extension Education, Bangladesh Agricultural University, Mymensingh.

Anonymous, 2008. Yearbook of Bangladesh Bureau of Statistics (Crop Statistics). Peoples Republic of Bangladesh, Dhaka, 5 p.

Anonymous, 2009. Statistical Pocket Book Bangladesh, Yearbook of Bangladesh 
Bureau of Statistics (BBS). Peoples Republic of Bangladesh, Dhaka, 208 p.

Haque, M. E., Hasan, S. S. and Khalil, M. I.. 2004. Use of Sources by the Farmers in Receiving Information Related to Cultivation of Modern Variety of Rice. Bangladesh Journal of Extension Education, 16 (2): 33-38.

Kothari, C. R. 2004. Research Methodology Methods \& Techniques, $2^{\text {nd }}$ Edn., New Age Publication, New Delhi, India.

Mondol, M. A. S., M. F. Chowdhury and M. M. Bahadur. 2005 Effect of Existing Homestead Agroforestry on the Socieconomic Development in Two Selected Upazilas of Dinajpur District of
Bangladesh. Bangladesh Journal of Training and Development, 18 (1\&2): 79-86.

Mondol, M. F and Mrittunjoy, R. 1988. Adunik Fal Baggan (Modern Fruit Science), $1^{\text {st }}$ edn., Club Bhoban, BAU, Mymensingh, $45 \mathrm{p}$.

Moniruzzaman, F. M. 1988. Bangladesh Faler Chash (Fruit Cultivation in Bangladesh), $2^{\text {nd }}$ Edition, Bangla Academy, Dhaka.

Rahman, M. L. 1995. Farmers' knowledge on Improved Practices of Potato Cultivation. M. Sc. thesis, Department of Agricultural Extension Education, Bangladesh Agricultural University, Mymensingh 